\title{
RISCOS E INCERTEZAS MANIFESTOS NO VALOR ECONÔMICO DE UM INVESTIMENTO: UM ESTUDO DE CASO DA OGX PETRÓLEO E GÁS
}

\section{RISKS AND UNCERTAINTIES MANIFESTED IN THE ECONOMIC VALUE OF AN INVESTMENT: A CASE STUDY OF OGX PETRÓLEO E GÁS}

\section{Recebimento: 18/09/2017- Aceite: 20/11/2017- Publicação: 23/12/2017 Processo de Avaliação: Double Blind Review}

Rogerio de Paiva Savegnago ${ }^{1}$

Mestre em Ciências Contábeis e Atuariais pela Pontifícia Universidade Católica de São Paulo- PUCSP

rogeriops75@icloud.com

Álvaro José Soncini

Mestre em Ciências Contábeis e Atuariais pela Pontifícia Universidade Católica de São Paulo- PUCSP

ajsoncini@hotmail.com

Antonio Benedito da Silva Oliveira

Professor Doutor do Mestrado da Pontifícia Universidade Católica de São Paulo (PUCSP) absolive@pucsp.br

\section{RESUMO}

No mercado financeiro e de capitais brasileiro, muitas são as opções de investimentos para os poupadores de recursos. Entretanto, a decisão por tais opções dependerá basicamente do perfil do investidor e do retorno esperado do ativo a que se queira investir. Tendo em vista a questão do retorno sob a forma de expectativa da geração de fluxos de caixa futuros, somados aos riscos diversos e à incerteza, tanto sob o aspecto macroeconômico quanto do próprio negócio da empresa investida, pode-se afirmar, de início, que a subjetividade utilizada na avaliação de um ativo ou um negócio seja um dos itens considerados na definição do seu valor econômico. Nesse sentido, o objetivo central deste artigo é analisar como o risco e a incerteza, aliados à formação das expectativas na avaliação de um investimento, se manifestam na formulação do seu valor econômico. A pesquisa documental deste trabalho foi focada na análise da empresa OGX Petróleo e Gás S.A. (OGX) compreendendo o período de 2008 a 2015. Alguns anos após a abertura de seu capital, foi constatado, pela OGX, que boa parte dos ativos anteriormente reconhecidos não apresentavam viabilidade na exploração de petróleo e gás natural, resultando no reconhecimento em seu resultado de perdas na forma de impairment, o que ocasionou a queda do valor de suas ações. Desse modo, com base nos resultados apresentados neste

\footnotetext{
${ }^{1}$ Autor para correspondência: Pontifícia Universidade Católica de São Paulo - PUCSP- R.: Monte Alegre, 984- Perdizes- São Paulo- SP- Brasil CEP05014-90.
}

Revista ENIAC Pesquisa, Guarulhos (SP), V.6, n.2, jun.- dez. 2017 
estudo, pode-se inferir que o risco e a incerteza, aliados a formação das expectativas, tiveram forte influência na avaliação do valor econômico da ação da OGX.

PALAVRAS-CHAVES: Valor Econômico. Subjetividade. Avaliação de Investimentos. Risco e Incerteza.

\section{ABSTRACT}

The Brazilian financial and capital markets provide several investment options for an investor. However, the decision behind such options will depend on both investor profile and the investment returns. Having in mind that such return can be seen as the investor's expectations of future cash flows from an investment, added to several risks and the uncertainty from such investment, macroeconomically speaking and even from the invested company itself, one could affirm that the subjectivity used in the valuation of an asset or a business would be one of the items considered in the definition of its economic value. In this sense, the main objective in this paper is to analyze how risk and uncertainty, allied to the formation of expectations in an investment valuation, can be manifested in its economic value. The research made for this paper was focused on the analysis of OGX Petróleo e Gás, a Brazilian publicly traded company, related to the period from 2008 to 2015. Some years after its IPO process, this company assessed that the assets once recognized could not be realized given the infeasibility on the exploration of oil and gas, resulting in the impairment of such assets and its recognition as losses by this company, contributing for the decline of its stock prices at the local exchange. Based on the results presented in this paper, the authors inferred that risk and uncertainty, allied to the formation of expectations, had strong influence on the valuation of the economic value of the OGX share.

KEYWORDS: Economic Value. Subjectivity. Investment Valuation. Risk and Uncertainty.

\section{INTRODUÇÃO}

Atualmente, no mercado financeiro e de capitais brasileiro, muitas são as opções de investimentos para os poupadores de recursos financeiros. Neste contexto, deve ser considerado que a decisão dentre estas várias opções dependerá basicamente do perfil do investidor e do retorno esperado do ativo a que se queira investir.

Investir no mercado de capitais é uma dessas opções. Segundo Assaf Neto (2014b, p. 205), a função básica desse mercado é "promover a riqueza nacional por meio da participação da poupança de cada agente econômico" e as ações seriam os principais ativos negociados nesse mercado. Dessa forma, ao investir o seu excedente de poupança em determinada companhia, tal investidor se torna proprietário de uma parcela do seu patrimônio. Adicionalmente, Assaf Neto ainda afirma que as empresas que recebem esses investimentos possuem melhores condições financeiras para tornarem viáveis os seus projetos de investimento, tanto pela captação de tais recursos juntos aos investidores, como pelo baixo comprometimento do caixa da companhia (ibid.).

Entretanto, antes de investir em determinada companhia, listada em Bolsa de Valores, o investidor se depara logo de início com o preço de mercado de sua ação. Segundo Fortuna (2013, p. 583), “o preço de uma ação em bolsa é o fruto das condições de mercado (oferta e demanda), que reflitam as condições estruturais e comportamentais da economia do País e específicas da empresa e de seu setor econômico". Adicionalmente, Oliveira e

Revista ENIAC Pesquisa, Guarulhos (SP), V.6, n.2, jun.- dez. 2017 
Pacheco (2011, p. 144) contribuem para o entendimento da formação do preço de determinada ação: "O custo de qualquer ativo, hoje, depende dos fluxos de caixa futuros previstos. Com as ações ocorre o mesmo. Assim, o preço de uma ação é consequência do fluxo de caixa futuro previsto para a empresa emissora, ou então dos lucros futuros projetados".

Tendo em vista a questão da expectativa da geração de fluxos de caixa futuros, somados aos riscos diversos e à incerteza, tanto sob o aspecto macroeconômico quanto do próprio negócio da empresa investida, pode-se afirmar, de início, que a subjetividade utilizada na avaliação de um ativo ou um negócio é um dos itens considerados na definição do seu valor econômico.

Nesse sentido, o objetivo geral deste artigo é analisar como o risco e a incerteza, aliados à formação das expectativas na decisão de investimento, se manifestam na avaliação do seu valor econômico. Portanto, pretende-se aqui verificar como a subjetividade envolvida nessa avaliação pode impactar a decisão por um investimento. Por conta do objetivo ora proposto, surge então o problema de pesquisa deste estudo: como o risco e a incerteza se manifestam na avaliação econômica de um ativo, considerando-se a sua subjetividade?

Dessa forma, espera-se uma contribuição à utilidade da informação relativa à formação do preço de um investimento, especificamente através da análise da subjetividade associada ao risco e à incerteza que influenciam na formação das expectativas dos investidores acerca do valor econômico de tal investimento.

Cabe ainda destacar que este artigo é uma pesquisa exploratória, ou seja, apesar de possuir base em uma estratégia de pesquisa bibliográfica e documental, ainda carece, na opinião dos pesquisadores autores, de mais estudos em outras empresas e grupos para que os achados aqui obtidos possam ser generalizados e relacionados de forma segura com o conhecimento anterior sobre o assunto A pesquisa bibliográfica deste estudo foi realizada com base em livros e trabalhos acadêmicos referentes aos temas aqui propostos. Já a pesquisa documental está focada no estudo de caso da empresa OGX Petróleo e Gás S.A. (OGX), relativamente ao período de dezembro de 2008 a dezembro de 2015, através de análises qualitativa e quantitativa das informações pesquisadas, quais sejam: o histórico das operações da companhia até a abertura do seu capital em 2008 e as comparações, por correlação, da variação do preço histórico de mercado de suas ações com as variações do valor de seus ativos imobilizado e intangível (incluindo o impairment desses ativos), do Ibovespa e do preço do barril do petróleo no mercado internacional.

\section{VALOR ECONÔMICO DE UM INVESTIMENTO}

\subsection{O INVESTIDOR E SUAS EXPECTATIVAS}

Segundo Oliveira, Guerreiro e Pereira (2001), o valor econômico de determinado recurso incorpora as expectativas desse agente quanto ao futuro. Assim é natural que, para qualquer decisão de investimento, haja uma expectativa de retorno por parte do investidor relacionado ao ativo que se queira investir. Nesse sentido, segundo esses autores, um tomador de decisão racional não pagaria por um bem um valor superior ao benefício que ele poderia lhe trazer. Esse benefício (futuro) se traduz no valor econômico de um ativo (ibid.).

Sob essa perspectiva, é natural esperar que, para determinada opção de investimento, sua atratividade ocorra de forma proporcional ao retorno esperado. Como bem destaca Assaf 
Neto (2014a, p. 8): “O investimento do acionista revela atratividade econômica somente quando a remuneração oferecida for suficiente para remunerar o custo de oportunidade do capital próprio aplicado no negócio". Desse modo, uma simples conceituação de custo de oportunidade refere-se ao quanto um investidor deixou de ganhar por não ter aproveitado outras oportunidades de investimento disponíveis (2014a, p. 1).

Uma vez entendido o conceito de custo de oportunidade de um investimento, faz-se necessário retornar ao conceito de valor econômico de um investimento, o qual, no seu devido tempo, deve resultar em fluxos de caixa futuros para o investidor. Damodaran (2004, p. 116) afirma que "em geral, o valor de qualquer ativo é o valor presente dos fluxos de caixa esperados desse ativo, e ele é determinado pelo tamanho dos fluxos de caixa, a taxa de crescimento esperada nesses fluxos de caixa, e a incerteza associada ao recebimento deles". Tal conceito apresentado por Damodaran elucida um importante componente associado ao valor econômico de um ativo: a incerteza associada ao recebimento dos fluxos de caixa futuros.

\subsection{O RISCO E A INCERTEZA ASSOCIADOS À AVALIAÇÃO DE UM INVESTIMENTO}

Dos fatores que podem impactar as expectativas de um investidor quanto a eventos futuros relacionados a uma opção de investimento, possivelmente os itens mais relevantes são o risco e a incerteza sobre esses eventos. Knight (1921, p. 20), trata da distinção entre incerteza e risco, definindo o risco como mensurável e a incerteza como não-mensurável. ${ }^{1}$ Ambos os termos têm uma distinção quase semântica, pois a conceituação de um e de outro dependem do grau de imprecisão relacionado às estimativas, sendo risco aquilo que pode ser mensurado com algum grau de precisão, tendo como base ocorrências possíveis ou estados futuros que podem ser quantificados em uma variável; e a incerteza aquilo que não pode ser avaliado, por envolver situações pouco comuns, que não se repetem ou que não podem ter as suas probabilidades determinadas (MARTINS, 2001, p. 310).

$\mathrm{O}$ risco e a incerteza normalmente são vistos sob um aspecto negativo. Entretanto, em se tratando dos negócios das empresas, podem ser vistos também sob um aspecto positivo, como propõe Oliveira (2014, p. 250): "A existência do risco e da incerteza faz existir o lucro que, de outra forma, tenderia a desaparecer pela livre competição. Assim, saber algo sobre o futuro, mas não tudo, torna necessário planejar, decidir, buscando lidar com os cenários possíveis.". Esse caminho mostra que o empresário ou mesmo o investidor podem ver uma oportunidade de ganho ao assumir determinado risco. Martins (2001, p. 312) afirma que o risco é aceito quando existe um prêmio associado a esse risco. Dessa forma, em circunstâncias normais, para que possa compensar o investimento em um negócio arriscado, o investidor exige um retorno elevado. Assim, segundo o autor, a relação risco versus retorno é fator fundamental para a tomada de decisão (ibid.)

\subsection{MENSURAÇÃO DO VALOR DE UM INVESTIMENTO}

Segundo Assaf Neto (2014a, p.200) os métodos de avaliação produzem estimativas do valor da empresa seguindo seus pressupostos e metodologias, sendo importante destacar que produzem um valor estimado e não definitivo. Já Perez e Famá $(2003$, p. 48) afirmam 
que "O processo de avaliação de empresas consiste na busca de um valor econômico, ou seja, um valor que expresse o potencial de geração futura de riqueza da empresa".

Um exemplo de modelo de mensuração do valor econômico de um ativo incorporando o seu risco é sugerido por Oliveira (2014, p. 207), no qual considera que os fluxos de caixa periódicos, relacionados a um ativo, devem ser estimados considerando uma realização provável, não totalmente certa, mas, sobre a qual se pode definir um campo de expectativas possíveis. Esses fluxos refletiriam um valor esperado (média provável ponderada), o qual seria descontado a uma taxa que reflete a oportunidade apropriada, dentro de um enfoque de probabilidade subjetiva. Dessa forma, o modelo é representado como segue:

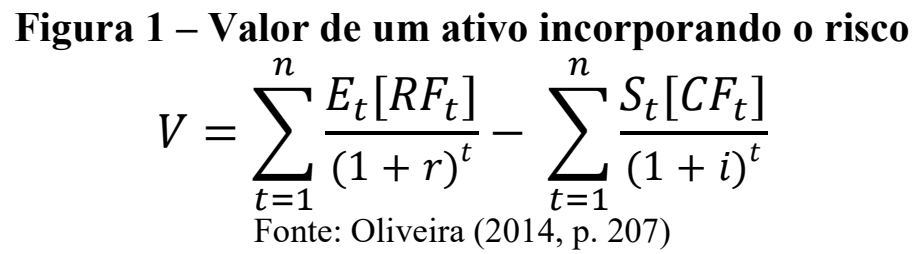

No modelo apresentado na figura $1, \mathrm{~V}=$ valor do ativo; $\mathrm{Et}=$ probabilidade de ocorrência das entradas de caixa; $\mathrm{RFt}=$ valor esperado do benefício futuro; $\mathrm{St}=$ probabilidade de ocorrência das saídas de caixa; $\mathrm{CFt}=$ valor esperado das saídas de caixa futuras, ponderadas pela sua probabilidade de ocorrência; $i=$ custo de oportunidade para as saídas de caixa; $r$ = custo de oportunidade para as entradas de caixa; $t$ = período.

Adicionalmente ao modelo proposto acima, há diversas técnicas de avaliação de investimentos disponíveis no mercado, das mais simples às mais complexas. Os modelos que possibilitam verificar com mais precisão o potencial de geração futura de riqueza da empresa acabam sendo os mais utilizados. Entre os modelos existentes aquele que mais se destaca é o fluxo de caixa descontado, sendo o mais utilizado e considerado como o mais confiável segundo pesquisa realizada por Martins et al. (2008).

Para Damodaran (2004, p. 611), em uma avaliação de fluxo de caixa descontado, estima-se o valor de qualquer ativo, redescontando os fluxos de caixas esperados sobre ele a uma taxa de desconto que reflete o seu grau de risco. De certa forma, é utilizada para mensurar o valor intrínseco de um ativo. As estimativas são realizadas com base em premissas, de acordo com as expectativas futuras, sendo que os fatores macroeconômicos devem ser incluídos nessas premissas, pois influenciam o futuro das empresas.

Outro método largamente utilizado para avaliação de empresas é o de avaliação por múltiplos. Segundo Perez e Famá (2003, p. 51), dada a sua aparente simplicidade de cálculos, a avaliação baseada em múltiplos é um método muito utilizado em avaliação de empresas.

A avaliação de empresas por múltiplos procura descobrir o valor corrente dos ativos, através da comparação com outros valores de empresas entendidas como comparáveis. Com isso, a empresa em avaliação replica a forma como as empresas comparáveis foram avaliadas, admitida como correta para a sua análise (ASSAF NETO, 2014a, p. 205).

Revista ENIAC Pesquisa, Guarulhos (SP), V.6, n.2, jun.- dez. 2017 
Um outro modelo de mensuração bem comum e que representa o valor de mercado de uma empresa é o do Patrimônio Líquido a Preços de Mercado que, segundo Assaf Neto (2014b, p. 253), é obtido pela multiplicação do valor das ações de uma empresa pela quantidade de ações emitidas. Dessa forma, se uma empresa emitiu 1 milhão de ações ordinárias e o preço de cada ação é cotado na Bolsa a $\mathrm{R} \$ 20,00$, o seu valor de mercado é de $\mathrm{R} \$ 20$ milhões.

Para a finalidade deste estudo, faz-se necessário igualmente compreender a mensuração dos ativos imobilizados e intangível sujeitos ao teste de recuperabilidade, mais conhecido no mercado por teste de impairment, instituído no ordenamento contábil através do CPC 01. Esse teste representa uma mudança relevante na contabilidade, pois permitiu que as demonstrações financeiras refletissem de maneira mais fidedigna o valor econômico de alguns itens do ativo.

Um ativo apresenta problemas de recuperação quando o seu valor contábil excede o seu valor recuperável. As empresas devem fazer esse teste anualmente ou quando há qualquer indicação de problema na recuperação de determinado ativo. Para estabelecer o valor recuperável de um ativo, deve-se escolher o que for maior entre o seu valor de uso e o valor justo, subtraídos dos custos para alienar tal ativo. Caso o valor escolhido seja inferior ao valor contábil, a diferença deve ser reconhecida no resultado como perda por impairment. Esse lançamento pode ser revertido caso haja alteração no cenário e o valor contábil do ativo volte a ser superior ao valor reduzido do impairment (exceto para o goodwill).

\section{METODOLOGIA}

Para se analisar como o risco e a incerteza se manifestam na avaliação econômica de um ativo considerando-se a sua subjetividade, foi escolhida como estratégia de pesquisa a realização de um estudo de caso da empresa OGX Petróleo e Gás S.A.

Inicialmente, através de pesquisa documental, extraiu-se do prospecto de abertura de capital $^{2}$ da companhia algumas informações relevantes para a análise dos dados da pesquisa, quais sejam: o histórico da OGX até a abertura de capital, bem como a situação em que a companhia se encontrava à época; a composição do capital social em quantidade de ações e valores integralizados pelos sócios majoritário e minoritários antes do IPO (Initial Public Offering) e a comparação do percentual de participação de cada um; a composição do balanço patrimonial e a abertura do ativo intangível na data-base 31 de março de 2008; o detalhamento dos riscos que os potenciais investidores estariam sujeitos por ocasião do IPO; e os investimentos oriundos do IPO com os novos percentuais de participação do sócio majoritário em relação aos demais acionistas, bem como o percentual de participação daquele em relação aos demais sócios.

A partir dessas informações introdutórias, partiu-se para a tabulação dos dados utilizados para esta pesquisa. Para tal foram utilizadas as bases de dados da BM\&FBovespa (informações contábeis da OGX), da Thomson Reuters ${ }^{3}$ (cotação das ações da OGX e do Ibovespa) e do Investing.com ${ }^{4}$ (cotação do petróleo no mercado internacional), compreendidas entre os anos de 2008 a 2015, em períodos semestrais.

Inicialmente foi realizada uma análise gráfica do preço da ação da OGX para o período proposto. Essas informações foram posteriormente comparadas com o Ibovespa. 
Essas duas variáveis foram então comparadas através do índice de correlação, calculado através do programa de computador Microsoft Excel.

A partir das demonstrações financeiras e demonstrações financeiras intermediárias da OGX, foram tabuladas informações referentes aos ativos imobilizado, intangível e aos saldos contabilizados como impairment. Posteriormente foi calculado com o uso do Microsoft Excel o índice de correlação, para a comparação entre o saldo semestral dos ativos imobilizados mais intangíveis e a cotação da ação da OGX. Posteriormente foram igualmente comparados pela mesma métrica o preço da ação da OGX e a cotação do preço do petróleo em dólar dos Estados Unidos.

\section{RESULTADOS}

Tendo em vista o objetivo proposto neste artigo, que é o de analisar como o risco e a incerteza, aliados à formação das expectativas na avaliação de um investimento, se manifestam na avaliação de seu valor econômico, neste item seguem os resultados da pesquisa, iniciando-se pelo histórico das operações da OGX até a abertura do seu capital, passando pela análise da evolução do preço de sua ação e do valor econômico de seus ativos imobilizado e intangível, buscando uma correlação entre a variação dessas duas variáveis. Em seguida, são comparadas as variações dos preços dessa ação e do preço do barril do petróleo no mercado internacional, para que se possa verificar uma possível correlação entre os preços desses dois ativos.

\subsection{HISTÓRICO DAS OPERAÇÕES DA OGX ATÉ A ABERTURA DE CAPITAL}

O ano de 2008 não foi um bom ano para a economia mundial, pois representava o início da crise econômica gerada pelos títulos sub-prime, lastreados em financiamentos hipotecários realizados nos Estados Unidos. Naquele momento a crise ainda era recente e havia incertezas e especulações a respeito dos seus impactos para Brasil e o restante do mundo. De imediato, no Brasil a crise trouxe impactos nas cotações de bolsa de valores e também nos processos de aberturas de capital, denominados IPO. Até então, o número de ofertas públicas havia aumentado desde 2004, até atingir o pico de sessenta ofertas em 2007. Em 2008 foram apenas três processos de IPOs, sendo um deles o da OGX (OLIVEIRA, 2011, p. 40).Mesmo com essa queda no volume de ofertas, no momento de abertura de capital da OGX as revistas de negócios à época demonstravam um certo otimismo para o setor petrolífero e de gás natural, principalmente devido ao crescimento da Petrobrás e às suas recentes descobertas relacionadas ao Pré-Sal, que poderiam supostamente fazer o Brasil aumentar significativamente sua produção de petróleo no futuro. Esse otimismo do setor gerou uma grande expectativa na abertura de capital da OGX, combinado também com o prestígio que até então gozava seu fundador e proprietário majoritário, Eike Batista.

Antes da abertura de capital em 2008, a OGX já havia recebido contribuições de capital de alguns investidores institucionais qualificados e também outro aporte de capital do sócio controlador. A tabela a seguir demonstra a composição do capital da OGX (em milhares de reais) no momento inicial, com contribuição de R\$ 22 milhões do sócio controlador e no momento que antecede ao seu IPO, com as contribuições adicionais mencionadas na ordem de $\mathrm{R} \$ 2,324$ bi, totalizando $\mathrm{R} \$ 2,346$ bi. 
Tabela 1 - Composição do capital social da OGX antes do IPO

\begin{tabular}{|c|c|c|c|c|c|}
\hline & \multicolumn{3}{|c|}{ Em R\$ mil } & & \\
\hline Investidores & $\begin{array}{l}\text { Capital } \\
\text { Inicial }\end{array}$ & $\begin{array}{c}\text { Investimentos } \\
\text { Adicionais }\end{array}$ & TOTAL & $\mathbf{N}^{\circ}$ Ações & $\begin{array}{l}\text { Ações } \\
(\%)\end{array}$ \\
\hline Eike Batista & 22.001 & 700.766 & 722.767 & 19.189 .308 & $72,7 \%$ \\
\hline Outros investidores & - & 1.623 .411 & 1.623 .411 & 7.196 .025 & $27,3 \%$ \\
\hline TOTAL & 22.001 & 2.324.177 & 2.346.178 & 26.385.333 & $100,0 \%$ \\
\hline
\end{tabular}

Fonte: Elaborado pelos autores com base em informações de Prospecto de abertura de capital OGX (2008).

No momento da entrada dos novos investidores, a OGX realizava suas primeiras aquisições de concessões de exploração e produção de petróleo. A Tabela 2 a seguir demonstra o balanço patrimonial sintético da empresa antes do IPO, no qual se pode verificar que a maior parte dos recursos até então captados haviam sido aplicados na aquisição desses investimentos.

Tabela 2 - Balanço patrimonial levantado em 31 de março de 2008

\begin{tabular}{l|r|l|r}
\hline \multicolumn{1}{c|}{$\begin{array}{c}\text { Total de Ativo } \\
\text { (Em R\$ mil) }\end{array}$} & $\mathbf{2 . 8 8 7 . 2 1 3}$ & \multicolumn{1}{|c|}{$\begin{array}{c}\text { Total de Passivo } \\
\text { (Em R\$ mil) }\end{array}$} & $\mathbf{2 . 8 8 7 . 2 1 3}$ \\
\hline Disponibilidades & 828.545 & Fornecedores & 697 \\
Imobilizado & 8.141 & $\begin{array}{l}\text { Contas a pagar por aquisição de } \\
\text { blocos exploratórios }\end{array}$ & 535.842 \\
Intangível & 2.015 .565 & Outros Passivos Não Circulantes & 13.215 \\
\hline Outros Ativos Não Circulantes & 34.962 & Patrimônio Líquido & 2.337 .459 \\
\hline
\end{tabular}

Fonte: Elaborado pelos autores com base em informações de Prospecto de abertura de capital OGX (2008).

Antes da abertura de capital, conforme os dados do prospecto do IPO, verificou-se que a OGX era uma empresa em estágio pré-operacional, sem nenhum histórico de operação. Só havia concessões, e a expectativa é que a Bacia de Campos seria a primeira a começar a gerar fluxos de caixa, a partir de 2011.

Apesar das expectativas quanto à capacidade de produção e faturamento da empresa, havia também um risco elevado nesse negócio, devido à natureza da operação e da OGX ainda ser uma empresa em fase pré-operacional, como já mencionado. Por conta desses motivos, a companhia informou de maneira clara, no prospecto de abertura de capital, todos os riscos que os investidores poderiam estar sujeitos, com destaque para: a incerteza inerente à previsão dos recursos naturais; a volatilidade dos preços do petróleo e do gás natural; dispêndios de capital projetados e dirigidos, bem como outros custos e obrigações; mudanças nas leis ambientais de regulação; concorrência; conflito de interesses (por haver um sócio controlador com poder de decisão total); e outros riscos oriundos de políticas macroeconômicas. 
Nessa operação poderia haver altos retornos, mas também havia um alto risco embutido, devido às incertezas sobre a operação, como destacado acima. O investidor ao entrar nesse investimento deveria acreditar que haveria petróleo e/ou gás natural nos campos em que a OGX obteve as concessões, deveria crer também que a OGX teria competência para extrair esses recursos com custos baixos e boa qualidade e, por último, acreditar que igualmente não haveria diminuição significativa nos preços de petróleo para os próximos anos. Outro ponto é que não se tratava, como visto, de uma empresa operacional em expansão em busca de novos ativos, mas de um empreendedor que captara recursos através da OGX para a realização de um novo negócio.

Mesmo com todos esses riscos, como já descrito, verificou-se que a OGX já havia captado R\$1,623 bilhão de outros sócios além de Eike Batista antes da abertura de capital. Com o processo de IPO, as cifras se tornariam maiores, conforme demonstrados a seguir (em R\$ mil):

Tabela 3 - Investimentos oriundos do IPO

\begin{tabular}{l|r|r|r|r|r|c}
\hline INVESTIDORES & $\begin{array}{c}\text { Capital } \\
\text { Inicial }\end{array}$ & $\begin{array}{c}\text { Investimentos } \\
\text { Adicionais }\end{array}$ & $\begin{array}{c}\text { Investimento } \\
\text { s IPO }\end{array}$ & TOTAL & No $^{\circ}$ Ações & $\begin{array}{c}\text { Ações } \\
\text { (\%) }\end{array}$ \\
\hline Eike Batista & 22.001 & 700.766 & 693.416 & 1.416 .183 & 19.802 .408 & $61,3 \%$ \\
Outros & - & 1.623 .411 & 6.018 .247 & 7.641 .658 & 12.517 .198 & $38,7 \%$ \\
\hline TOTAL & $\mathbf{2 2 . 0 0 1}$ & $\mathbf{2 . 3 2 4 . 1 7 7}$ & $\mathbf{6 . 7 1 1 . 6 6 3}$ & $\mathbf{9 . 0 5 7 . 8 4 1}$ & $\mathbf{3 2 . 3 1 9 . 6 0 6}$ & $\mathbf{1 0 0 \%}$ \\
\hline
\end{tabular}

Fonte: Elaborado pelos autores com base em informações de Prospecto de abertura de capital OGX (2008).

No prospecto de abertura de capital, os futuros acionistas são informados que os recursos recebidos na abertura de capital seriam empregados para desembolsos de capital relativos à campanha exploratória nos atuais blocos, com novas oportunidades de investimentos, no desenvolvimento inicial de descobertas esperadas, bem como na utilização como capital de giro para o pagamento de despesas gerais e administrativas.

Com base nos dados da Tabela 3, verificou-se que dos investimentos recebidos pela OGX, R \$ 7,641 bi foram realizados por acionistas minoritários e $\mathrm{R} \$ 1,416$ bi pelo acionista controlador. Essa diferença entre os montantes investidos pelo controlador e pelos demais investidores não é a mesma no que diz respeito ao seu percentual de participação na companhia, uma vez que o acionista controlador detinha $61,3 \%$ das ações, enquanto os minoritários detinham $38,7 \%$.

O total de ações emitidas pela companhia, após a abertura de capital, era de 32.319.606 e o valor da ação era de $\mathrm{R} \$ 1.131$, resultando em um patrimônio líquido a preços de mercado de $\mathrm{R} \$ 36,553$ bilhões, ressaltando-se que esse era o valor econômico do negócio ainda em fase pré-operacional. Dessa forma, tendo em vista esta situação e os montantes investidos nesta empresa, pode-se afirmar que este valor de mercado incorporava tão somente as expectativas desses investidores sobre o sucesso da companhia, na forma de geração de resultado futuro através da exploração de petróleo e gás natural. 


\subsection{ANÁLISE DA EVOLUÇÃO DO PREÇO DA AÇÃO DA OGX E SUA VARIAÇÃO NO PERÍODO PROPOSTO}

Conforme indicado em seu prospecto de abertura de capital, as ações da OGX foram vendidas inicialmente a R\$ 1.131. Em 18 de dezembro de 2009, conforme informado nas demonstrações financeiras da OGX relativamente ao mesmo período, houve um desdobramento das ações da companhia, de forma que, a partir daquele momento, uma ação ordinária passou a corresponder a cem ações ordinárias. Para tornar as análises deste artigo mais compreensíveis, considerou-se os efeitos desse desdobramento desde a data da abertura de capital. Partindo de tal premissa, o gráfico a seguir demonstra a variação do valor de mercado das ações da OGX no período de junho/2008 a dezembro/2015.

\section{Gráfico 1 - Análise do valor da ação da OGX entre junho/2008 a dezembro/2015}

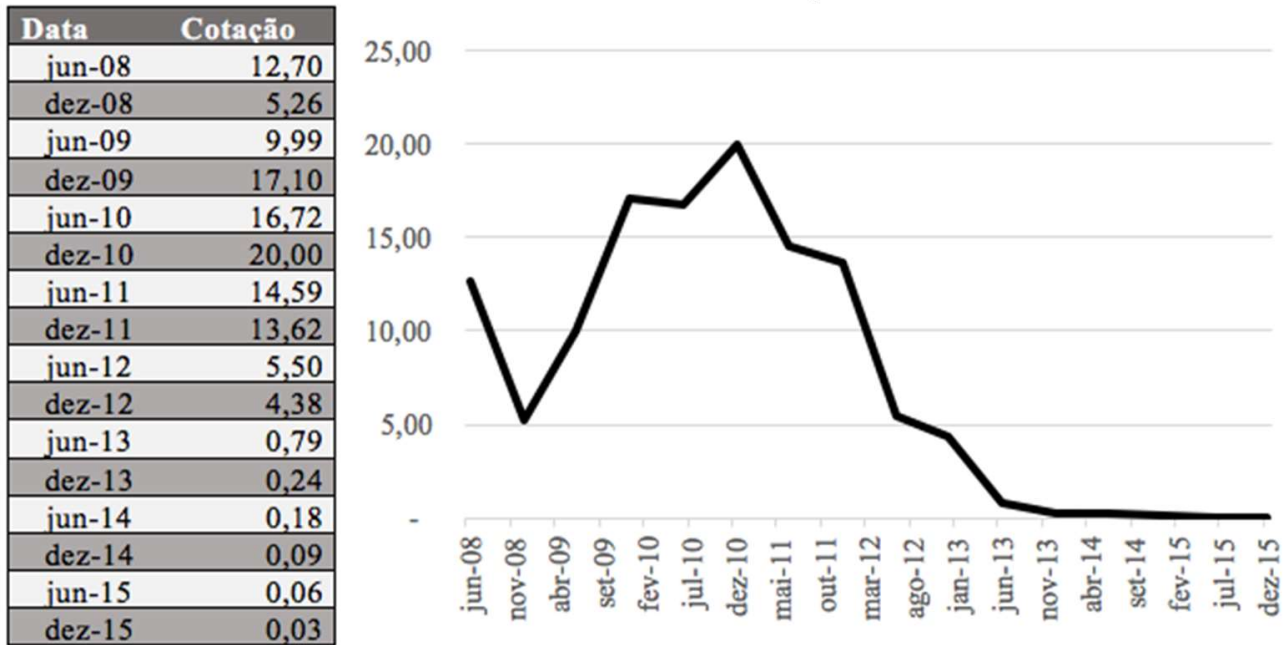

Fonte: Thomson Reuters

O gráfico 1 mostra o histórico das cotações da ação da OGX apenas no fim de cada semestre, demonstrando que a cotação dessa ação teve uma diminuição logo no início de sua comercialização em 2008, conseguindo se recuperar no final de 2009 e chegando à sua melhor cotação em dezembro de 2010. Após esse período, só houve diminuições, sendo que até 2011 a sua cotação ainda se encontrava acima do valor da ação na abertura de capital, o que passou a não ocorrer a partir de 2012 em diante.

Para complementar esta análise, optou-se por comparar a variação dessa ação com o Ibovespa, demonstrada na Tabela 4 a seguir. 
Tabela 4 - Comparação da ação da OGX com o Ibovespa

\begin{tabular}{|c|c|c|c|c|}
\hline \multirow{2}{*}{ Data } & \multicolumn{2}{|l|}{ OGX } & \multicolumn{2}{|l|}{ Ibovespa } \\
\hline & Cotação (em RS) & Variação & Cotação (em R\$) & Variação \\
\hline jun/08 & 12,7 & & $65.017,58$ & \\
\hline $\mathrm{dez} / 08$ & 5,26 & $-59 \%$ & $37.550,31$ & $-42 \%$ \\
\hline jun/09 & 9,99 & $90 \%$ & $51.465,46$ & $37 \%$ \\
\hline $\mathrm{dez} / 09$ & 17,1 & $71 \%$ & $68.588,41$ & $33 \%$ \\
\hline jun/10 & 16,72 & $-2 \%$ & $60.935,90$ & $-11 \%$ \\
\hline $\mathrm{dez} / 10$ & 20 & $20 \%$ & $69.304,81$ & $14 \%$ \\
\hline jun/11 & 14,59 & $-27 \%$ & $62.403,64$ & $-10 \%$ \\
\hline $\mathrm{dez} / 11$ & 13,62 & $-7 \%$ & $56.754,08$ & $-9 \%$ \\
\hline jun/12 & 5,5 & $-60 \%$ & $54.354,63$ & $-4 \%$ \\
\hline $\mathrm{dez} / 12$ & 4,38 & $-20 \%$ & $60.952,08$ & $12 \%$ \\
\hline jun/13 & 0,79 & $-82 \%$ & $47.457,13$ & $-22 \%$ \\
\hline $\mathrm{dez} / 13$ & 0,24 & $-70 \%$ & $51.507,16$ & $9 \%$ \\
\hline jun/14 & 0,18 & $-25 \%$ & $53.168,22$ & $3 \%$ \\
\hline $\mathrm{dez} / 14$ & 0,09 & $-50 \%$ & $50.007,41$ & $-6 \%$ \\
\hline jun/15 & 0,06 & $-33 \%$ & $53.080,88$ & $6 \%$ \\
\hline $\mathrm{dez} / 15$ & 0,03 & $-50 \%$ & $43.349,96$ & $-18 \%$ \\
\hline
\end{tabular}

Pela análise dos dados apresentados, verificou-se que de 2008 até 2011 o comportamento da ação da OGX vinha ocorrendo em consonância com a cotação do Ibovespa, demonstrado através do resultado do coeficiente de correlação de 0,92 entre estas duas variáveis. Entretanto, este comportamento foi reduzido significativamente entre os períodos de 2012 a 2015, por meio da apresentação do coeficiente de correlação de 0,64 , demonstrando que a variação do preço da ação da OGX a partir de 2015 não mais estava estatisticamente relacionada com os movimentos do Ibovespa.

\subsection{VALOR ECONÔMICO DOS ATIVOS IMOBILIZADO E INTANGÍVEL}

A seguir, seguem os saldos de imobilizado e intangível por semestres divulgados nas demonstrações financeiras, os quais terão a sua variação comparada à variação no valor da ação da OGX (valores em R\$ mil). 
Tabela 5 - Saldo de imobilizado em intangível de 2008 a 2015 (em R\$ mil)

\begin{tabular}{|cccc}
\hline Data & Imobilizado & Intangível & TOTAL \\
\hline $31 / 12 / 2008$ & 12.066 & 1.485 .430 & 1.497 .496 \\
\hline $30 / 06 / 2009$ & 16.980 & 2.052 .672 & 2.069 .652 \\
\hline $31 / 12 / 2009$ & 19.917 & 2.099 .559 & 2.119 .476 \\
\hline $30 / 06 / 2010$ & 21.600 & 3.159 .413 & 3.181 .013 \\
\hline $31 / 12 / 2010$ & 27.624 & 4.589 .418 & 4.617 .042 \\
\hline $30 / 06 / 2011$ & 66.008 & 5.932 .045 & 5.998 .053 \\
\hline $31 / 12 / 2011$ & 2.786 .425 & 922.615 & 3.709 .040 \\
\hline $30 / 06 / 2012$ & 8.172 .793 & 1.510 .418 & 9.683 .211 \\
\hline $31 / 12 / 2012$ & 8.971 .504 & 2.048 .103 & 11.019 .607 \\
\hline $30 / 06 / 2013$ & 6.077 .144 & 1.892 .810 & 7.969 .954 \\
\hline $31 / 12 / 2013$ & 2.985 .761 & 738.384 & 3.724 .145 \\
\hline $30 / 06 / 2014$ & 2.983 .287 & 737.006 & 3.720 .293 \\
\hline $30 / 12 / 2014$ & 518.699 & 675.065 & 1.193 .764 \\
\hline $30 / 06 / 2015$ & 553.454 & 573.982 & 1.127 .436 \\
\hline $30 / 12 / 2015$ & 639.917 & 571.933 & 1.211 .850 \\
\hline
\end{tabular}

Fonte: Demonstrações Financeiras e Demonstrações Financeiras Intermediárias da OGX.

Por meio da leitura da tabela 5, percebe-se que alguns saldos que estavam registrados como ativo intangível foram reclassificados para o imobilizado devido ao desenvolvimento das bacias e ao início de sua exploração. Como o objetivo deste item é a análise do valor econômico desses dois ativos em conjunto, estes serão considerados pela somatória do seu valor total.

O saldo total dos ativos sofreu uma redução significativa a partir do ano de 2013 devido ao reconhecimento de impairment. A Tabela 6 a seguir demonstra o reconhecimento no resultado dos valores globais a título de impairment em bases semestrais.

\begin{tabular}{cr} 
Tabela 6 - Impairment contabilizado por semestre \\
\hline Data & Impairment (em R\$ mil) \\
$31 / 12 / 2010$ & 76 \\
$31 / 12 / 2011$ & 664 \\
$30 / 06 / 2013$ & 3.644 .523 \\
$31 / 12 / 2013$ & 4.993 .515 \\
$30 / 06 / 2014$ & 4.474 \\
$30 / 12 / 2014$ & 2.731 .340 \\
$30 / 06 / 2015$ & $(87.820)$ \\
$30 / 12 / 2015$ & $(232.195)$ \\
\hline
\end{tabular}

Fonte: Demonstrações Financeiras e Demonstrações Financeiras Intermediárias da OGX. 
Em suas demonstrações financeiras, a OGX detalhou os saldos de impairment por campo e bacia. As justificativas gerais para o seu reconhecimento foram: o aumento nos custos esperados de logística; a queda no preço do barril do petróleo; a inexistência de tecnologia capaz de viabilizar economicamente a produção nos campos; e o prazo da concessão que estava chegando ao fim, apesar de as atividades exploratórias se encontrarem em fase inicial (portanto a renovação da concessão não era provável de ocorrer).

Note-se que, no item de políticas contábeis das demonstrações financeiras da OGX de 2013 e 2014 (principais períodos em que houve impairment), os acionistas foram informados que a administração realizava anualmente testes de impairment, comparando os fluxos de caixas projetados, trazidos a valor presente, com o valor contábil atual dos ativos sujeitos a esse cálculo. Os principais destaques a respeito dos critérios utilizados para esse teste pela OGX foram: os volumes de reserva e produção foram estimados por especialistas internos ou terceiros; o preço do barril foi estimado com base em projeções de bancos e agências especializadas; e a taxa média de desconto foi estimada em $10 \%$, levando em consideração o benchmark da indústria de petróleo.

As referidas baixas por impairment, realizadas pela companhia nos últimos anos, representam a perda efetiva do valor econômico de ativos imobilizados e intangíveis reconhecidos no passado. Aquele primeiro valor havia sido mensurado com base em expectativas associadas ao risco de reconhecimento das receitas de petróleo e gás natural no futuro, considerando que a cotação dessas commodities se mantivesse no mesmo nível do momento daquela mensuração. Adicionalmente, havia a incerteza sobre a viabilidade da exploração naquelas bacias, a qual se mostrou economicamente inviável como apresentado pela companhia.

Em 2015 foi a única exceção, com reconhecimento de mais recuperações das perdas provisionadas em períodos anteriores do que perdas por impairment no período.

\subsection{CORRELAÇÃO ENTRE AS VARIAÇÕES DO PREÇO DA AÇÃO E DO VALOR ECONÔMICO DOS ATIVOS IMOBILIZADO E INTANGÍVEL}

A Tabela 7 a seguir tem como objetivo demonstrar a variação do preço das ações comparadas à variação dos ativos imobilizado e intangível da OGX. 
Tabela 7 - Preço da ação comparado ao ativo imobilizado/intangível

\begin{tabular}{lccrr}
\hline Data & $\begin{array}{c}\text { OGX } \\
\text { Cotação } \\
\text { (em R\$) }\end{array}$ & Variação & $\begin{array}{c}\text { Imobilizado + Intangível } \\
\text { Saldo } \\
\text { (em R\$ mil) }\end{array}$ & Variação \\
\hline jun/08 & 12,70 & & 2.023 .706 & \\
\hline dez/08 & 5,26 & $-59 \%$ & 1.497 .496 & $-26 \%$ \\
\hline jun/09 & 9,99 & $90 \%$ & 2.069 .652 & $38 \%$ \\
\hline dez/09 & 17,10 & $71 \%$ & 2.119 .476 & $2 \%$ \\
\hline jun/10 & 16,72 & $-2 \%$ & 3.181 .013 & $50 \%$ \\
\hline dez/10 & 20,00 & $20 \%$ & 4.617 .042 & $45 \%$ \\
\hline jun/11 & 14,59 & $-27 \%$ & 5.998 .053 & $30 \%$ \\
\hline dez/11 & 13,62 & $-7 \%$ & 7.685 .507 & $28 \%$ \\
\hline jun/12 & 5,50 & $-60 \%$ & 9.683 .211 & $26 \%$ \\
\hline dez/12 & 4,38 & $-20 \%$ & 11.019 .607 & $14 \%$ \\
\hline jun/13 & 0,79 & $-82 \%$ & 7.969 .954 & $-28 \%$ \\
\hline dez/13 & 0,24 & $-70 \%$ & 3.724 .145 & $-53 \%$ \\
\hline jun/14 & 0,18 & $-25 \%$ & 3.720 .293 & $0 \%$ \\
\hline dez/14 & 0,09 & $-50 \%$ & 1.193 .764 & $-68 \%$ \\
\hline jun/15 & 0,06 & $-33 \%$ & 1.127 .436 & $-6 \%$ \\
\hline dez/15 & 0,03 & $-50 \%$ & 1.211 .850 & $7 \%$ \\
\hline
\end{tabular}

Fonte: Demonstrações Financeiras e Demonstrações Financeiras Intermediárias da OGX e Thomson Reuters.

O coeficiente de correlação entre o valor da ação e os saldos de ativo imobilizados somados aos ativos intangíveis para o período completo acima foi de 0,05 . Com base nessa informação, pode-se depreender que a variação do valor da ação da OGX não se relacionou diretamente com a variação dos ativos imobilizado e intangível, entre os períodos em que houve aquisições ou baixas de ativos (que não por impairment).

Entretanto, ao comparar as variáveis entre os períodos em que ocorreram as baixas devido ao impairment (2013 e 2014), a correlação calculada foi de 0,86 , ou seja, o preço da ação variou de acordo com as baixas do imobilizado e intangível, refletindo no mercado a mudança na expectativa do seu valor econômico, uma vez que as expectativas esperadas pela própria companhia não haviam sido concretizadas.

\subsection{COMPARAÇÃO ENTRE AS VARIAÇÕES DOS PREÇOS DA AÇÃO E DO BARRIL DO PETRÓLEO NO MERCADO INTERNACIONAL}

A Tabela 8 tem como objetivo demonstrar a variação do preço das ações comparadas à variação do barril de petróleo no mercado internacional. Foi utilizada a cotação deste último em dólar, que é uma moeda estável, para eliminar os efeitos de variação cambial. 
Tabela 8 - Preço da ação comparado ao barril do petróleo (em USD)

\begin{tabular}{c|cc|cc}
\hline \multirow{2}{*}{ DATA } & \multicolumn{2}{|c|}{ OGX } & \multicolumn{2}{c}{ Petróleo } \\
\cline { 2 - 5 } & $\begin{array}{c}\text { Cotação } \\
\text { (em R\$) }\end{array}$ & Variação & $\begin{array}{c}\text { Cotação } \\
\text { (em US\$) }\end{array}$ & Variação \\
\hline iun-08 & 12,70 & & 139,82 \\
dez-08 & 5,26 & $-59 \%$ & 45,59 & $-67 \%$ \\
jun-09 & 9,99 & $90 \%$ & 69,30 & $52 \%$ \\
\hline dez-09 & 17,10 & $71 \%$ & 77,93 & $12 \%$ \\
\hline jun-10 & 16,72 & $-2 \%$ & 75,01 & $-4 \%$ \\
\hline dez-10 & 20,00 & $20 \%$ & 94,75 & $26 \%$ \\
\hline jun-11 & 14,59 & $-27 \%$ & 112,48 & $19 \%$ \\
\hline dez-11 & 13,62 & $-7 \%$ & 107,38 & $-5 \%$ \\
\hline jun-12 & 5,50 & $-60 \%$ & 97,80 & $-9 \%$ \\
\hline dez-12 & 4,38 & $-20 \%$ & 111,11 & $14 \%$ \\
\hline jun-13 & 0,79 & $-82 \%$ & 102,76 & $-8 \%$ \\
\hline dez-13 & 0,24 & $-70 \%$ & 110,80 & $8 \%$ \\
\hline jun-14 & 0,18 & $-25 \%$ & 112,36 & $1 \%$ \\
\hline dez-14 & 0,09 & $-50 \%$ & 57,33 & $-49 \%$ \\
\hline jun-15 & 0,06 & $-33 \%$ & 63,59 & $11 \%$ \\
\hline dez-15 & 0,03 & $-50 \%$ & 37,28 & $-41 \%$ \\
\hline
\end{tabular}

Fonte: Thomson Reuters e Investing.com.

O coeficiente de correlação apresentado entre o valor da ação e o preço do barril de petróleo entre os períodos foi de 0,24 , demonstrando que no período acima o preço do barril explicou muito pouco das variações da cotação da ação da OGX.

\section{CONSIDERAÇÕES FINAIS}

Os modelos de avaliação de investimentos realizados pelos investidores devem buscar mensurar ao máximo o risco associado a determinado negócio. A subjetividade dessas mensurações deve ser tratada com métodos objetivos que permitam ao investidor quantificar os diferentes cenários para a tomada de decisão.

Entretanto, o investidor nem sempre tem acesso a todas as informações da empresa investida, e a quantidade e qualidade das informações disponíveis é um importante fator para a tomada de decisão de qual método para definição de seu valor deve ser escolhido. Um exemplo é o método de avaliação por fluxo de caixa descontado que, para ter mais sucesso em seus resultados, necessita de informações sobre o planejamento da empresa, 
além das definições sobre premissas macroeconômicas no futuro. O método de avaliação por múltiplos pode ser realizado com as informações disponíveis aos usuários externos, entretanto não tem o mesmo grau de qualidade de julgamento relacionado a eventos futuros.

As demonstrações contábeis disponibilizadas aos usuários externos têm como objetivo divulgar informações com poder preditivo aos investidores e credores. A qualidade dessas informações evoluiu muito com a implementação no Brasil das regras internacionais de contabilidade do IFRS (International Financial Reporting Standards), mas ainda existem limitações que não permitem que elas demonstrem o real valor econômico da empresa.

A OGX foi avaliada na data da abertura de capital por R $\$ 36,553$ bilhões. Segundo reportagem realizada na data da abertura de capital e publicada no website da revista Exame, esse foi o maior IPO da história da Bolsa de Valores brasileira, sendo a OGX a $12^{\circ}$ empresa em valor de mercado à época.

Os riscos desse investimento foram informados de maneira clara no prospecto de abertura de capital da companhia. Apesar desses riscos, havia uma expectativa tanto da empresa quanto dos seus investidores em relação à sua capacidade de gestão na produção de petróleo e gás natural, o que resultaria na geração de valor econômico para os acionistas. O fato da empresa estar em estágio pré-operacional não foi um impeditivo aos investidores que, mesmo assim, acreditaram no projeto e investiram seus recursos na companhia.

Alguns anos após a abertura de seu capital, foi constatado pela OGX que boa parte dos ativos anteriormente reconhecidos não apresentavam viabilidade na exploração dos recursos naturais citados, resultando no reconhecimento em seu resultado de perdas na forma de impairment.

Esse fato resultou na forte queda do valor de suas ações, como destacado no Gráfico 1, pois sem ter como extrair petróleo e gás natural a empresa não conseguiria produzir e consecutivamente gerar o valor econômico esperado por seus acionistas. Nesse sentido, o risco "Incerteza inerente à previsão dos recursos naturais", apontado no prospecto de abertura de capital, foi confirmado. O coeficiente de correlação de 0,86 , apresentado entre as variáveis ativo (intangível mais imobilizado), e valor da ação nos períodos que houve impairment confirmam este ponto. Já a queda no preço do barril de petróleo no mercado internacional pareceu não ter contribuído para a queda no valor das ações da OGX. Tal afirmação é corroborada através da inferência apresentada na análise de comparabilidade entre o valor da ação e o preço do barril do petróleo, de que não houve correlação entre essas variáveis (o coeficiente de correlação apresentado foi de 0,24 ).

Em 31 de dezembro de 2015, o valor da ação da OGX era de R $\$ 0,03$ e até o mês de abril de 2016 a empresa ainda se encontrava em processo de recuperação judicial. A perda de valor de mercado da OGX entre o período da abertura de capital em 2008 e a data de 31 de dezembro de 2015 foi de R $\$ 11,28$, desvalorizando $99,7 \%$ em relação ao seu valor inicial.

Supondo que um investidor tenha adquirido o lote mínimo de ações na abertura de capital, investindo R $\$ 300$ mil, caso ele não tenha vendido essa posição, o valor de mercado das ações, em 31 de dezembro de 2015, seria de $\mathrm{R} \$ 795,76$.

Os dados acima extraídos confirmam a hipótese apresentada neste artigo de que a subjetividade implícita no risco e na incerteza, manifestada na avaliação econômica de um 
ativo, decorre a partir de formação das expectativas dos investidores em relação aos fluxos de caixa esperados de um investimento.

Os investidores aplicaram recursos em uma empresa pré-operacional porque havia uma expectativa de que esses investimentos resultariam em ganhos futuros. Os dados disponíveis na data de abertura de capital eram baseados em estimativas com alto nível de subjetividade e os riscos do negócio estavam explícitos no prospecto de abertura de capital.

Com a impossibilidade de geração de recursos naturais em grande parte das jazidas, não havia mais a expectativa de produção e consecutivamente, de geração de fluxos de caixa futuro. A queda no preço do petróleo contribuiu para a inviabilidade da extração dos recursos naturais, pois os custos de extração excederiam os benefícios advindos da venda desses produtos. Não havendo expectativa de geração de fluxo de caixa, a OGX perdeu significativamente o seu valor de mercado, o que contribuiu para que não conseguisse liquidez suficiente no mercado financeiro para dar continuidade às suas operações, entrando em estado de recuperação judicial.

Com base nos resultados apresentados neste estudo, pode-se inferir que o risco e a incerteza, aliados à formação das expectativas, tiveram forte influência na avaliação do valor econômico da ação da OGX.

\section{REFERÊNCIAS}

ASSAF NETO, Alexandre. Valuation: métricas de valor \& avaliação de empresas. São Paulo, Atlas, 2014a.

Mercado financeiro. 12a. ed. São Paulo: Atlas, 2014b.

COMITÊ DE PRONUNCIAMENTOS CONTÁBEIS (CPC). Pronunciamento CPC 01

Redução ao valor recuperável de ativos. Disponível em http://www.cpc.org.br/CPC/Documentos-

Emitidos/Pronunciamentos/Pronunciamento?Id=2. Acesso em: 5 set. 2015

DAMODARAN, Aswath. Finanças corporativas: teoria e prática. Trad. Jorge Ritter. 2 ed. Porto Alegre: Bookman, 2004.

FORTUNA, Eduardo. Mercado financeiro: produtos e serviços. 19a. ed. Rio de Janeiro: Qualitymark Editora, 2013.

KNIGHT, Frank H. Risk, uncertainty and profits. Boston: Houghton Mifflin, 1921. Disponível em: $<$ https://ia902708.us.archive.org/28/items/riskuncertaintyp00knigrich/riskunc ertaintyp00knigrich.pdf $>$. Acesso em: 30 ago. 2015.

MARTINS, Eliseu (Org.). Avaliação de empresas: da mensuração contábil à econômica. São Paulo: Atlas, 2001. 
MARTINS, Eliseu; MACHADO, Marcia Regina; SOUTE, Dione Olesczuk; SCHVIRCK, Eliandro; Métodos de avaliação utilizados pelos profissionais de investimento. Revista Unb Contábil, Brasília, 11(1-2): 1-17, jan/dez. 2008.

OLIVEIRA, Antonio Benedito Silva; GUERREIRO, Reinaldo; PEREIRA, Carlos Alberto. A incerteza na Mensuração e Informação do Valor Econômico: um outro paradoxo do valor. In: CONGRESSO IIC - ACODI 2001. Anais... Leon, 2001. Disponível em: $<$ http://www.intercostos.org/documentos/Trabajo050.pdf>. Acesso em: 15 ago. 2015.

OLIVEIRA, Antonio Benedito Silva. Controladoria - Fundamentos do controle empresarial. 2a. ed. São Paulo: Saraiva. 2014.

OLIVEIRA, Bruno Cals. Fatores determinantes para abertura de capital de empresas brasileiras. 2011. Dissertação (Mestrado em Administração) - Faculdade de Economia Administração e Contabilidade, da Universidade de São Paulo, São Paulo, 2011.

OLIVEIRA, Gilson; PACHECO, Marcelo. Mercado financeiro: objetivo e profissional. 2a. ed. São Paulo: Editora Fundamento Educacional, 2011.

PEREZ, Marcelo Monteiro; FAMÁ, Rubens. Método de avaliação de empresas e balanço de determinação. Caderno de Pesquisa Administração, São Paulo, 10(4): 47-59, out/dez. 2003.

\footnotetext{
1 "There are other ambiguities in the term 'risk' as well, which will be pointed out; but this is the most important. It will appear that a measurable uncertainty, or 'risk' proper, as we shall use the term, is so far different from an unmeasurable one that it is not in effect an uncertainty at all. We shall accordingly restrict the term "uncertainty" to cases of the non-quantitative type" (KNIGHT, 1921, p. 20).

${ }^{2}$ Disponível em <www.ogx.com.br /download_arquivos.asp?id_arquivo=DAFA1611-A80F-4409-A8A411C1F4B68D89\&tipo=53296>. Acesso: em 10 set. 2015.

${ }^{3}$ Disponível em <www.thomsonreuters.com.br>. Acesso em: 15 abr. 2016.

${ }^{4}$ Disponível em $<$ br.investing.com $>$. Acesso em: 15 abr. 2016.
} 